\title{
Effect of the Angiotensin II Receptor Antagonist Losartan on Uric Acid and Oxypurine Metabolism in Healthy Subjects
}

\author{
Toshihiro Hamada, Ichiro Hisatome, Yoshiharu Kinugasa, Koichi Matsubara, Hideki Shimizu, \\ Hiroaki Tanaka, Masako Furuse, Kazuhiko Sonoyama, Yasutaka Yamamoto, Akira Ohtahara, \\ Osamu Igawa, Chiaki Shigemasa and Tetsuya Yamamoto*
}

\begin{abstract}
Objective The acute effects of the angiotensin II receptor antagonist losartan on uric acid and oxypurine metabolism were evaluated.

Methods Losartan $(50 \mathrm{mg})$ was administered orally to 6 healthy males. Blood and urine samples for uric acid and oxypurine were collected before and up to 6 hours after losartan administration. The same examinations were performed later using enalapril (5 mg).

Results Losartan decreased the serum uric acid concentration (from 5.9 \pm 0.9 to $5.2 \pm 1.0 \mathrm{mg} / \mathrm{dl}$ ) and increased its fractional clearance, which reached a maximum after 2 hours, while enalapril did not. Losartan also induced an increase in the plasma concentration of hypoxanthine, peaking in the fourth hour, and a decrease in its urinary clearance, while the plasma xanthine concentration and its urinary clearance were unchanged. The extent of uric acid excretion was much greater than that of the oxypurines.

Conclusions Losartan, which has a high affinity for the urate/anion exchanger, has a transient uricosuric effect. Our data indicate that losartan induces a significant decrease in the urinary excretion of hypoxanthine without changes in xanthine.
\end{abstract}

(Internal Medicine 41: 793-797, 2002)

Key words: antihypertensive agents, urate metabolites, urinary excretion, healthy volunteers

\section{Introduction}

For hypertensive patients with hyperuricemia, blood pressure should be lowered with antihypertensive drugs that have a favorable effect on uric acid metabolism. Several angiotensinconverting enzyme inhibitors, including captopril and enalapril, have demonstrated a beneficial effect on the serum uric acid level by increasing urinary uric acid excretion in hypertensive patients $(1,2)$. Several calcium channel antagonists are also known to have uricosuric effects $(3,4)$. The angiotensin II receptor antagonist losartan has demonstrated significant uricosuric activity and has been found to lower serum uric acid concentrations (5-7). Puig et al (8) observed that losartan, but not eposartan, increased the serum concentration and fractional excretion of uric acid in hypertensive patients. Furthermore, losartan significantly increased the urinary excretion of purine bases and oxypurinol in healthy subjects treated with allopurinol (9). If losartan decreases the plasma concentration of xanthine as well as hypoxanthine, the precursor of uric acid, the reduction of plasma precursor of uric acid might contribute to the reduction of uric acid.

In the present study, we investigated the effects of losartan on uric acid and oxypurine metabolism in healthy subjects without allopurinol treatment and compared these effects with those of the angiotensin-converting enzyme inhibitor enalapril.

\section{Design and Methods}

Six Japanese healthy male volunteers (age 24 to 28 years, mean $26 \pm 2$ years; mean body mass index 22.6 \pm 3.6 ) gave their informed consent and participated in the study. None of them had hypertension, diabetes mellitus or albuminuria. They received losartan (50 mg, BANYU Pharmaceutical Co., Ltd., Tokyo) orally and were permitted to consume water freely in order to obtain $>100 \mathrm{ml} / \mathrm{h}$ of urine samples. Blood pressure and pulse rate were measured every 30 minutes during the study. Blood and urine samples were collected before the experiment and 1, 2, 4, 6 hours after drug administration. Uric acid and creatinine levels were measured in serum and urine samples by an enzymatic method. Serum and urinary electrolyte concentrations were measured by standard automated procedures. Plasma and urinary oxypurine (hypoxanthine and xanthine) concentrations were measured by high performance liquid chro-

From the Department of Cardiovascular Medicine, Tottori University Hospital, Yonago and *theThird Department of Internal Medicine, Hyogo College of Medicine, Nishinomiya

Received for publication November 5, 2001; Accepted for publication April 10, 2001

Reprint requests should be addressed to Dr. Toshihiro Hamada, the Department of Cardiovascular Medicine, Tottori University Hospital, 36-1 Nishimachi, Yonago, Tottori 683-8504 
matography (HPLC). Plasma concentration of losartan and its active metabolite E-3174 were kindly measured by BANYU Pharmaceutical Co., Ltd. The same examinations were performed later using angiotensin-converting enzyme inhibitor, enalapril (5mg, BANYU Pharmaceutical Co., Ltd., Tokyo).

Values are expressed as the mean \pm standard deviation. The significance of differences in data before and after administra-

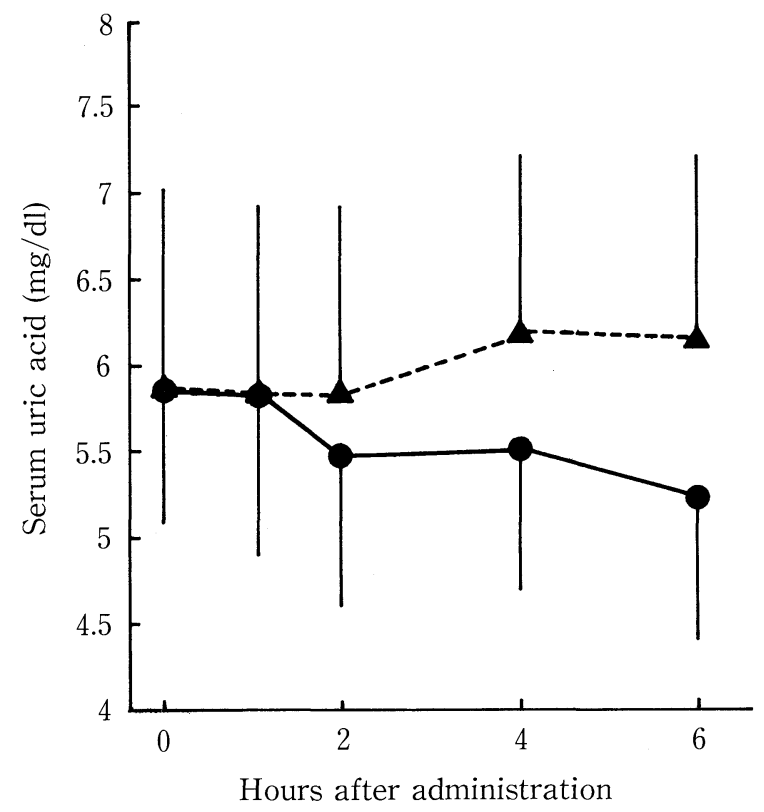

A

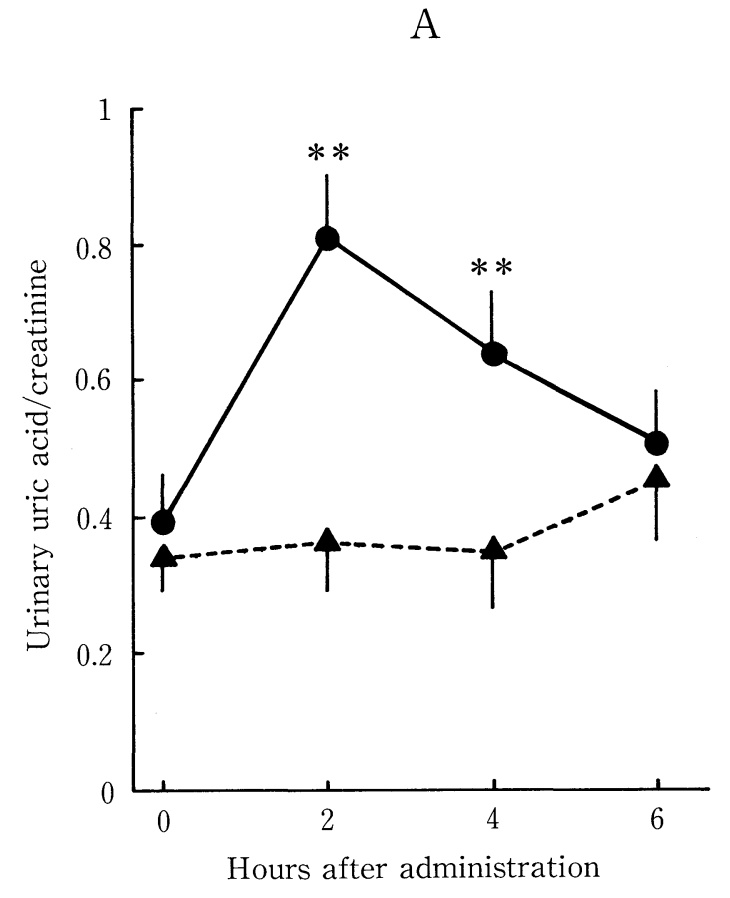

C tion was tested by two-way analysis of variance (ANOVA) of repeated measurement. A p value of less than 0.05 was considered statistically significant.

\section{Results}

Both losartan and enalapril lowered mean blood pressure to

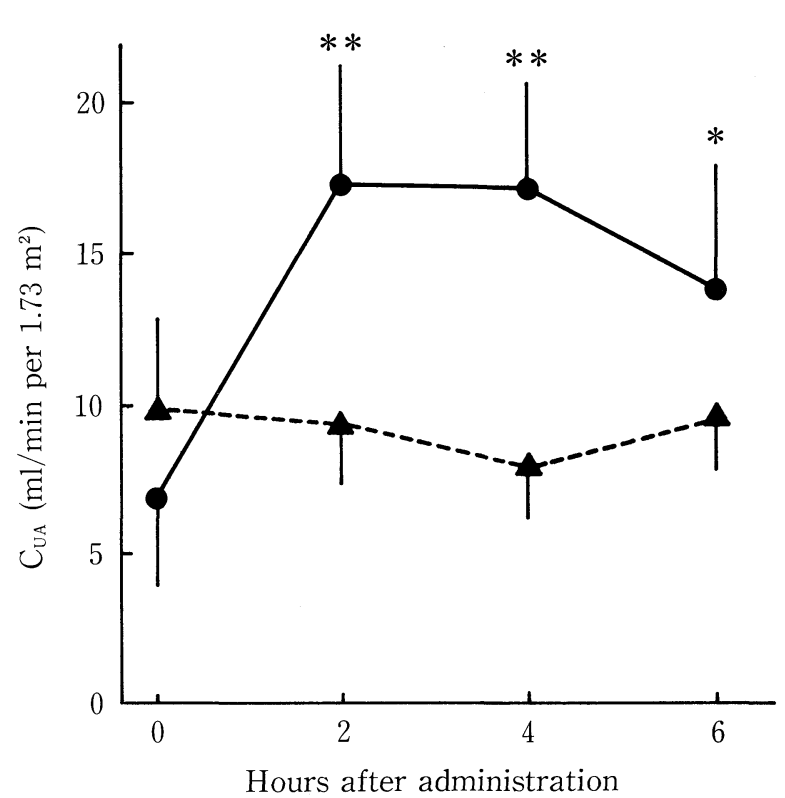

B

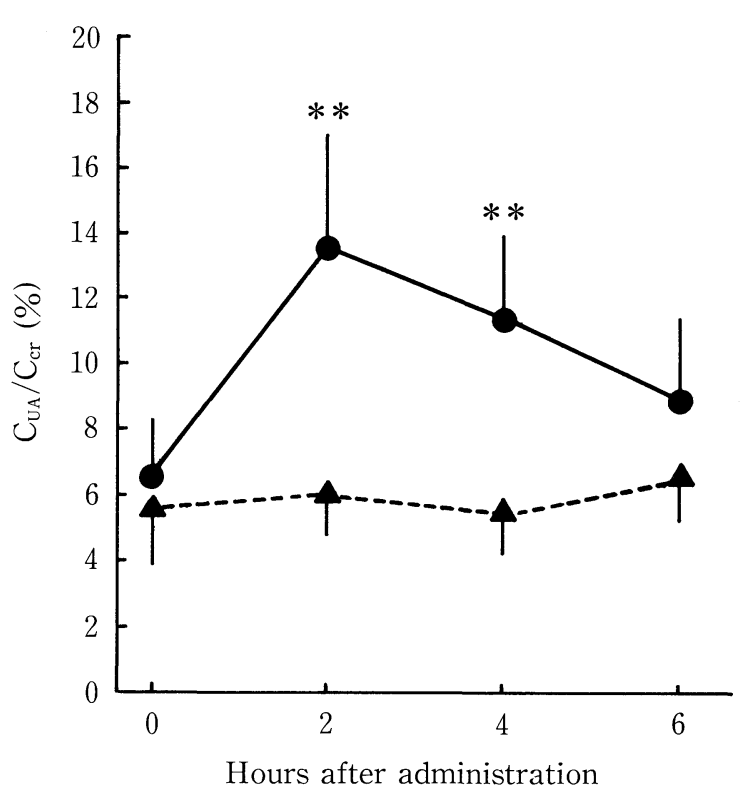

$\mathrm{D}$

Figure 1. Graph showing the variation in serum uric acid concentration $(A)$, uric acid clearance $C_{U A},(B)$, urinary uric acid/ creatinine $(C)$ and fractional excretion of uric acid $\mathrm{C}_{\mathrm{UA}} / \mathrm{C}_{\mathrm{cr}},(\mathrm{D})$ before and after administration of losartan (closed circle) and enalapril (closed triangle). ${ }^{*} \mathbf{p}<0.05, * * p<0.01$ vs pretreatment period. 
the same extent ( $83 \pm 11$ to $73 \pm 8 \mathrm{mmHg}$ and $82 \pm 8$ to $73 \pm 5$ $\mathrm{mmHg}$, respectively). Losartan induced a significant 3.95-fold increase in plasma angiotensin II, while enalapril did not induce an increase (0.86-fold). The two agents did not influence the plasma aldosterone concentration $(85 \pm 31$ to $85 \pm 34 \mathrm{pg} / \mathrm{ml}$ with losartan, and $79 \pm 24$ to $77 \pm 14 \mathrm{pg} / \mathrm{ml}$ with enalapril). During the experiment, losartan and enalapril increased urinary fractional sodium excretion in the same extent, which peaked in the second hour after drug administration (FENa; $0.71 \pm 0.23 \%$ to $1.17 \pm 0.40 \%, \mathrm{p}<0.05$; and $0.80 \pm 0.24 \%$ to $1.13 \pm 0.42 \%, \mathrm{p}<0.05$, respectively). The two drugs did not significantly influence creatinine clearance $(145 \pm 40$ to $156 \pm 17$ $\mathrm{ml} / \mathrm{min} / \mathrm{m}^{2}$ per $1.48 \mathrm{~m}^{2}$ with losartan, and $168 \pm 14$ to $153 \pm 30$ $\mathrm{ml} / \mathrm{min} / \mathrm{m}^{2}$ per $1.48 \mathrm{~m}^{2}$ with enalapril).

Baseline serum uric acid concentration, uric acid clearance, and creatinine clearance were not statistically different before each treatment. As shown in Fig. 1A, Losartan induced a slight time-dependent decrease in the serum uric acid concentration from $5.9 \pm 0.9$ to $5.2 \pm 1.0 \mathrm{mg} / \mathrm{dl}$, while enalapril did not $(5.9 \pm 1.2$ to $6.2 \pm 1.1 \mathrm{mg} / \mathrm{dl}$ ). Uric acid clearance (which increased from $6.9 \pm 3.3 \mathrm{ml} / \mathrm{min} / \mathrm{m}^{2}$ per $1.48 \mathrm{~m}^{2}$ before treatment to $17.4 \pm 4.0$ $\mathrm{ml} / \mathrm{min} / \mathrm{m}^{2}$ per $1.48 \mathrm{~m}^{2}$ after treatment, $\left.\mathrm{p}<0.01\right)$ was also elevated 2 and 4 hours after losartan administration (Fig. 1B). Losartan also induced significant increases in the urinary uric acid/creatinine ratio $(0.40 \pm 0.06$ to $0.82 \pm 0.09, \mathrm{p}<0.01)$ and the fractional uric acid excretion $(4.7 \pm 1.6 \%$ to $13.6 \pm 3.8 \%, \mathrm{p}<0.01)$, all of which reached a maximum value after 2 hours (Fig. 1C, 1D).

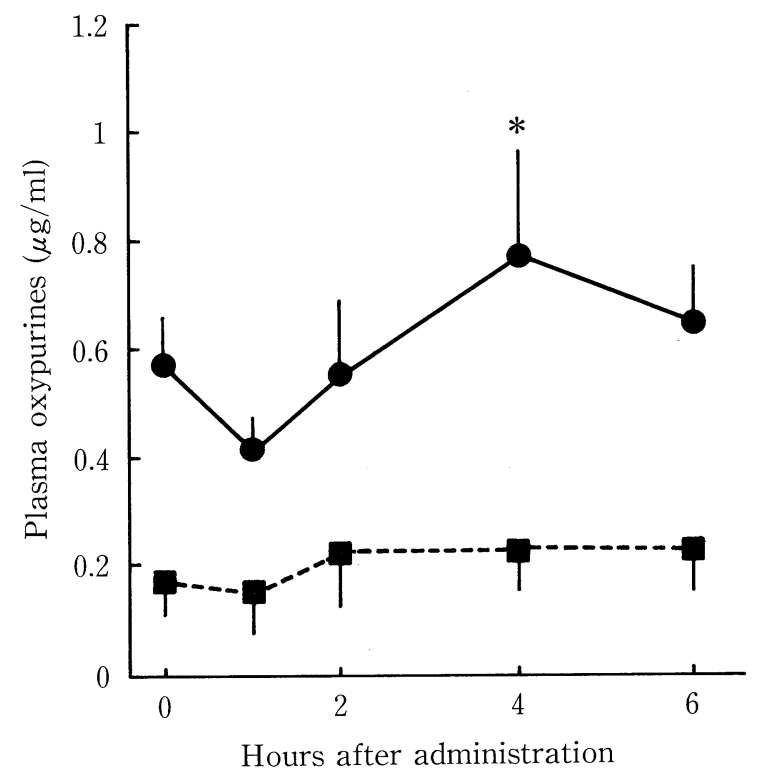

A
Losartan significantly increased the plasma concentration of hypoxanthine $(0.58 \pm 0.08 \mu \mathrm{g} / \mathrm{ml}$ to $0.83 \pm 0.16 \mu \mathrm{g} / \mathrm{ml}, \mathrm{p}<0.01)$, peaking in the fourth hour. Losartan did not increase the xanthine concentration significantly $(0.17 \pm 0.04 \mu \mathrm{g} / \mathrm{ml}$ to $0.23 \pm 0.09$ $\mu \mathrm{g} / \mathrm{ml}$ at 6 hours, $\mathrm{p}=0.24$; Fig. $2 \mathrm{~A}$ ). Losartan induced timedependent decreases in the urinary hypoxanthine/creatinine ratio $\left(1.35 \pm 1.07 \times 10^{-2}\right.$ to $\left.0.47 \pm 0.06 \times 10^{-2}, \mathrm{p}<0.05\right)$ and the fractional excretion of hypoxanthine $(23.5 \pm 18.9 \%$ to $6.5 \pm 2.2 \%$, $\mathrm{p}<0.05$ ), whereas the urinary xanthine/creatinine ratio and the fractional excretion of xanthine were unchanged (Fig. 2B). On the other hand, enalapril did not significantly change the plasma concentration and urinary clearance of either hypoxanthine or xanthine (data not shown).

After losartan administration, the peak plasma losartan concentration was reached at one hour $(238 \pm 163 \mathrm{ng} / \mathrm{ml})$ and the plasma losartan concentration was lowered significantly at 2 hours $(129 \pm 97 \mathrm{ng} / \mathrm{ml}$ at 2 hours, $35 \pm 10 \mathrm{ng} / \mathrm{ml}$ at 4 hours and $17 \pm 9 \mathrm{ng} / \mathrm{ml}$ at 6 hours). The active metabolite E-3174 was found to have a longer half-life than losartan $(352 \pm 86 \mathrm{ng} / \mathrm{ml}$ at 2 hours, $341 \pm 126 \mathrm{ng} / \mathrm{ml}$ at 4 hours and $211 \pm 70 \mathrm{ng} / \mathrm{ml}$ at 6 hours).

\section{Discussion}

In the present study, losartan had no effect on the glomerular filtration rate of normotensive subjects. During the investigation, sufficient urine samples were obtained to avoid changes in glomerular filtration rate and urate reabsorption into the renal tubule. Losartan induced transient significant increases in

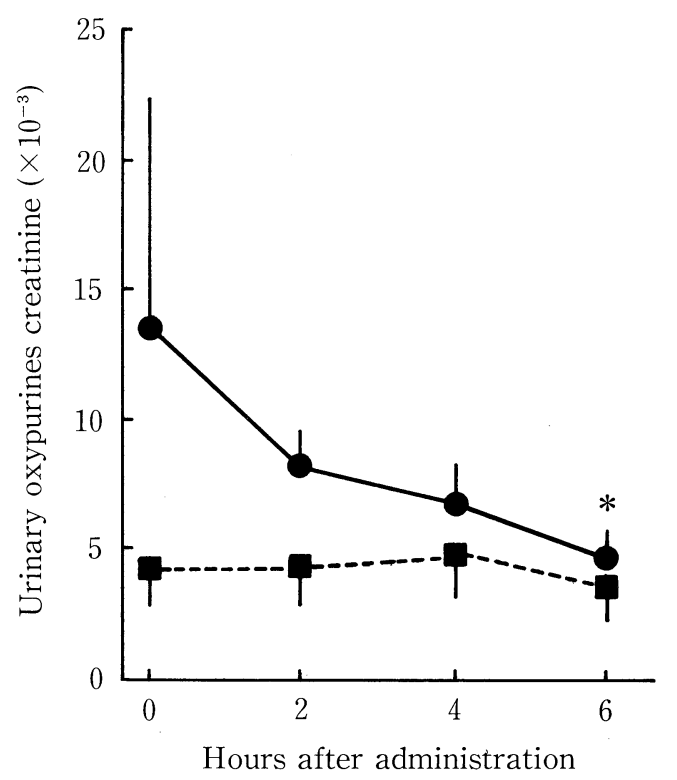

$\mathrm{B}$

Figure 2. Graph A demonstrates the variation in plasma hypoxanthine concentration (closed circle) and plasma xanthine concentration (closed square) before and after losartan administration. Graph B demonstrates the variation in urinary hypoxanthine/creatinine (closed circle) and urinary xanthine/creatinine (closed square) before and after losartan. ${ }^{*}$ p $<0.05$ vs pretreatment period. 
urinary excretion, urinary clearance, and fractional excretion of uric acid, accompanied by increases in plasma oxypurine concentrations without changes in urinary oxypurine clearance. Our data support the notion of the potent inhibitory effect of the parent compound of losartan on the urate/anion transport in the human renal proximal tubule presented by Burnier et al (6) and Roch-Ramel et al (9). The time course of uric acid excretion was consistent with that of the changes in the plasma losartan concentration. Thus, our data suggest that losartaninduced uricosuria is not related to the renin-angiotensin system but to a specific characteristic of the losartan molecule. According to Sweet et al (10), the fractional excretion of uric acid was not significantly altered by intravenous administration of E-3174, the main active metabolite of losartan.

On the other hand, uricosuric effect was not observed with the angiotensin-converting enzyme inhibitor, enalapril in the present study. Although several reports have indicated that captopril and enalapril have a uricosuric effect $(1,2)$ in 4 weeks after their administration, these studies did not demonstrate the acute effect of angiotensin-converting enzyme inhibitor on lowering serum uric acid concentrations several hours after administration of a single drug dose. According to Schmitt et al (11) and Tikkanen et al (12), captopril and enalapril did not lower the serum uric acid concentration by increasing urinary uric acid excretion in hypertensive patients. Although angiotensin-converting enzyme inhibition may augment urate secretion into human proximal renal tubules, the effect of losartan on urate/anion transport is thought to be more potent than that of captopril and enalapril. Furthermore, we demonstrated that losartan and enalapril lower mean blood pressure and induce an acute increase in urinary sodium excretion without any influence on the glomerular filtration rate or plasma aldosterone concentrations. It is generally recognized that the extent of urinary urate reabsorption is dependent on that of urinary sodium reabsorption. However, our data indicate that losartan, but not enalapril, increases urinary urate excretion after a single dose administration; the losartan-induced uricosuric effect is not mediated by the increase in urinary sodium excretion.

Since losartan increases plasma hypoxanthine and xanthine concentrations, it is necessary to discuss whether losartan or E-3174 directly inhibit xanthine oxidase activity, leading to reduced uric acid synthesis or increased oxypurine synthesis. Thus, we attempted to investigate the effects of losartan and E-3174 on plasma and urinary concentrations of oxypurines and on xanthine oxidase activity. According to our preliminary study, losartan and E-3174 did not inhibit xanthine oxidase activity in an in vitro experiment (data not shown).

Losartan has a transient uricosuric effect, on the other hand it induced a decrease in the urinary excretion of hypoxanthine in the present study. Since uric acid, oxypurinol and xanthine partly share the renal transporter, a decrease in oxypurine clearance cannot be explained by the inhibitory effect of losartan on the urate/anion transport in the human renal proximal tubule as presented by Burnier et al (6) and Roch-Ramel et al (9). Yamamoto et al (13) reported that losartan (100 mg) combined with allopurinol lower the plasma concentrations of uric acid, xanthine and oxypurinol and increase their urinary excretion of oxypurinol at 3 hours after losartan administration. However, losartan did not alter the renal transport of hypoxanthine, of which the result is opposite that of our data. According to their investigation, changes in uric acid metabolism and oxypurinol were investigated during short intervals, while plasma E-3174 concentration was unchanged; also they would have found an increase in oxypurine clearance. As they found higher plasma oxypurine and losartan concentrations than in the present study, furthermore, as they used allopurinol, higher plasma hypoxanthine concentrations would be reached compared to our study, and their fractional excretion of oxypurine was over $100 \%$, indicating that oxypurines were secreted into renal tubules throughout their study. On the contrary, we used losartan, while hypoxanthine tended to be absorbed into the renal tubule. Therefore, losartan might induce a decrease in hypoxanthine clearance while xanthine clearance is unchanged under lower plasma oxypurine concentration. Losartan might induce an increase in urinary xanthine excretion while the plasma oxypurine concentration is elevated with allopurinol. These data indicate that hypoxanthine might be transported via pathways different from those of uric acid, oxypurinol and xanthine (14). Our data may indicate that E-3174 partially acts on one of any renal oxypurine transporters, except for the urate/ anion transport and inhibits secretion of hypoxanthine into renal tubules. Further studies are necesary to investigate the effect of E-3174 on the renal transport pathway of uric acid and oxypurines.

No part of the work has been published or is under consideration for publication.

\section{References}

1) Leary WP, Reyes AJ, Acosta-Barrios TN, Maharaj B. Captopril once daily as monotherapy in patients with hyperuricemia and essential hypertension. Lancet 1: 1277, 1985 (letter).

2) Navis GJ, DeLong PE, DeZeeuw D. Serum uric acid, ACE inhibitors and natriuresis. Lancet 2: 156, 1985 (letter).

3) Faulds D, Sorkin EM. Ferodipine.A review of the pharmacology and therapeutic use of the extended release formulation in older patients. Drugs Aging 2: 374-388, 1992.

4) Iimura $O$, Shimamoto $K$. Efficacy and mode of action of manidipine: a new calcium channel antagonist. Am Heart J 125 (2 pt 2): 635-641, 1993.

5) Nakashima M, Uematsu T, Kosuge K, Kanamaru M. Pilot study of the uricosuric effect of DuP-753, a new angiotensin II receptor antagonist, in healthy subjects. Eur J Clin Pharmacol 42: 333-335, 1992.

6) Burnier M, Roch-Ramel F, Brunner HR. Renal effects of angiotensin II receptor blockade in normotensive subjects. Kidney Int 49: 1787-1790, 1996.

7) Edwards RM, Trizna W, Stack EJ, Weinstock J. Interaction of nonpeptide angiotensin II receptor antagonists with the urate transporter in rat renal brush-border membranes. J Pharmacol Exp Ther 276: 125-129, 1996.

8) Puig JG, Mateos F, Buno A, Ortega R, Rodriguez F, Dal-Fe R. Effect of eprosartan and losartan on uric acid metabolism in patients with essential hypertension. J Hypertens 17: 1033-1039, 1999.

9) Roch-Ramel F, Guisan B, Diezi J. Effects of uricosuric and antiuricosuric agents on urate transport in human brush-border membrane vesicles. $\mathrm{J}$ Pharmacol Exp Ther 280: 839-845, 1997.

10) Sweet CS, Bradstreet DC, Berman RS, Jallard N, Saenz A, Weidler DJ. 


\section{Losartan and Purine Metabolism}

Pharmacodynamic activity of intravenous E-3174, an angiotensin II antagonist, in patients with essential hypertension. Am J Hypertens 7: 10351040, 1994.

11) Schmitt F, Natov S, Martinez F, Lacour B, Hannedouche TP. Renal effects of angiotensin I - receptor blockade and angiotensin convertase inhibition in man. Clin Sci 90: 205-213, 1996.

12) Tikkanen I, Omvik P, Jansen HA. Comparison of the angiotensin II antagonist losartan with the angiotensin converting enzyme inhibitor enalapril in patients with essential hypertension. J Hypertens 13: 1343-1351, 1995.

13) Yamamoto T, Moriwaki Y, Takahashi S, Tsutsumi Z, Hada T. Effect of losartan potassium, an angiotensin II receptor antagonist, on renal excretion of oxypurinol and purine bases. J Rheumatol 27: 2232-2236, 2000.

14) Yamamoto T, Moriwaki Y, Takahashi S, Hada T, Higashino K. Renal excretion of purine bases. Effects of probenecid, benzbromarone and pyrazinamide. Nephron 48: 116-120, 1988. 